\title{
CYBERSECURITY LEADERS: KNOWLEDGE DRIVING HUMAN CAPITAL DEVELOPMENT
}

\author{
Sharon L. BURTON \\ slburton@captech.edu
}

CAPITOL TECHNOLOGY UNIVERSITY, GREATER WASHINGTON, D.C.

\begin{abstract}
Cybersecurity leaders must be able to use critical reading and thinking skills, exercise judgment when policies are not distinct and precise, and have the knowledge, skills, and abilities to tailor technical and planning data to diverse customers' levels of understanding. Ninety-three percent of cybersecurity leaders do not report directly to the chief operating officer. While status differences influence interactions amid groups, attackers are smarter. With the aim of protecting organizations and reducing risk, knowledge about security must increase. Understanding voids are costly and increased breach chances are imminent. Burning questions exist. What are needed technological learnings for cybersecurity leaders to become smarter and remain ahead of attackers? How might these technologies hasten the understanding of the 'what, ' 'how,' and 'why' reasons and key drivers for organizational behaviors. This article offers comparative analyses for cybersecurity leaders to engage in the questioning of practices, scrutinize entrenched assumptions about technology, customary practices, and query technology's outputs by pursuing to comprehend all assumptions that could influence operations. Because understanding continues to rely upon progressively multifaceted epistemic technologies, outcomes of the research suggest that the salience of status distinctions is of central significance to the development of ongoing and proactive technological learning and up scaling solutions.
\end{abstract}

\section{KEYWORDS:}

Artificial intelligence, augmented reality, cybersecurity leadership, hype cycles, human capital development

\section{Introduction}

Building an interdisciplinary learning system for cybersecurity leaders to continually sharpen their knowledge, skills, and ability (Burton, 2014; HIMSS, 2021a) is required to thwart even the most sophisticated hackers and attackers
(Burrell, 2021). Namely, interruptions subsist for advancing suitable cybersecurity training and controls within the critical infrastructure sectors; such concerns, forebodings, and failures leave the United States and others subjected to cyberattacks that could leave caustic, crushing, and damaging effects on 
security (Dawson et al., 2021; Muller, 2021; Olsen, 2020). This text posits that organizations, to include healthcare facilities, must investigate and infuse human capital development aspects for cybersecurity leadership instead of applying only a focus on increasing knowledge in cybersecurity and its intricacies as they relate to a technical, planning, and response operational standpoint (Burrell, 2021). Human capital development is people development. Applying the interdisciplinary approach to cybersecurity mindfulness is needed as the action references issue-driven concerns. However, having a seat at the table and a voice at the $\mathrm{C}$-suite level can establish increased security mindfulness throughout every organizational function. As personnel status differences continue to influence and derail interactions amid cybersecurity groups, attackers are becoming smarter.

The salient coordinates of the research are learnt from copious databases. Academic fee-based databases utilized are ABI Inform Complete (ProQuest), MEDLINE, Academic Search Premier (EBSCO), Business Source Premier (EBSO), ProQuest Dissertation Database, PubMed, Ebook Collection (EBSCO), Education Research Complete (EBSCO), and ERIC (EBSCO) Research. Association fee-based databases utilized are American Telemedicine Association (ATA). Internet searches useful include Telehealth Resource Centers.org, Department of Health and Human Services (telehealth, rural health), Healthcare.gov, Google Scholar, and recent peer reviewed literature. Additional literature data searches include the US National Library of Medicine, and the National Institutes of Health (NIH). Using the given databases and systems supported this researcher's faith in the sources of data scrutinized plus in the exactitude and influence of the data. The usage of the given subscription-based and examined databases reinforced recognition that the investigation and data underwent strict, painstaking, careful, and controlled evaluation systems, that define scholarly work (Saldaña, 2018).
Applying the interdisciplinary approach to human capital development means that no one learning and development action or sector can supply a response to the particulars of cybersecurity difficulty (Waltner-Toews, 2017). Applying transdisciplinary leadership learning can be challenging due to this leadership demanding knowledge fusion that directs obscurities, strictness, pied interactions, and risk sharing (Burton, 2014). With the aim of protecting organizations and reducing risk, overall cybersecurity knowledge must increase. Also, cybersecurity and organizational priorities must align. Cybersecurity leaders and risk management leaders must employ needed technologies where their organizational infrastructure could be at risk of compromise whether by external or internal threats (Shoard, 2020). Delimitations of this text includes the tool, hype cycles, and technologies artificial intelligence and augmented reality. A graphical presentation to understand the technology is the hype cycle.

\section{Comprehending hype cycles}

Hype cycles are frequently employed as reference points in technology and marketing reporting (Wigmore, 2021). Gartner: Global Research and Advisory Company stands as the global leading research and advisory company that offers leadership essential organization insights, information, and tools necessary to for organizations to realize their individual enterprise obligatory priorities for the purpose of shaping tomorrow's needs (Gartner, 2021a). The Gartner hype cycle, a graphical exemplification of the perceived worth of an individual technology trend or innovation to include the technology trend or innovation comparative market promotion. The hype cycle supports leaders to comprehend the manner and perceived worth of how a given technology progresses over the course of its maturity lifecycle (Gartner, 2021b). The maturity lifecycle is composed of five cycles that are noted on the $\mathrm{x}$-axis. See Figure no. 1 to understand the stages of the hype cycle. 


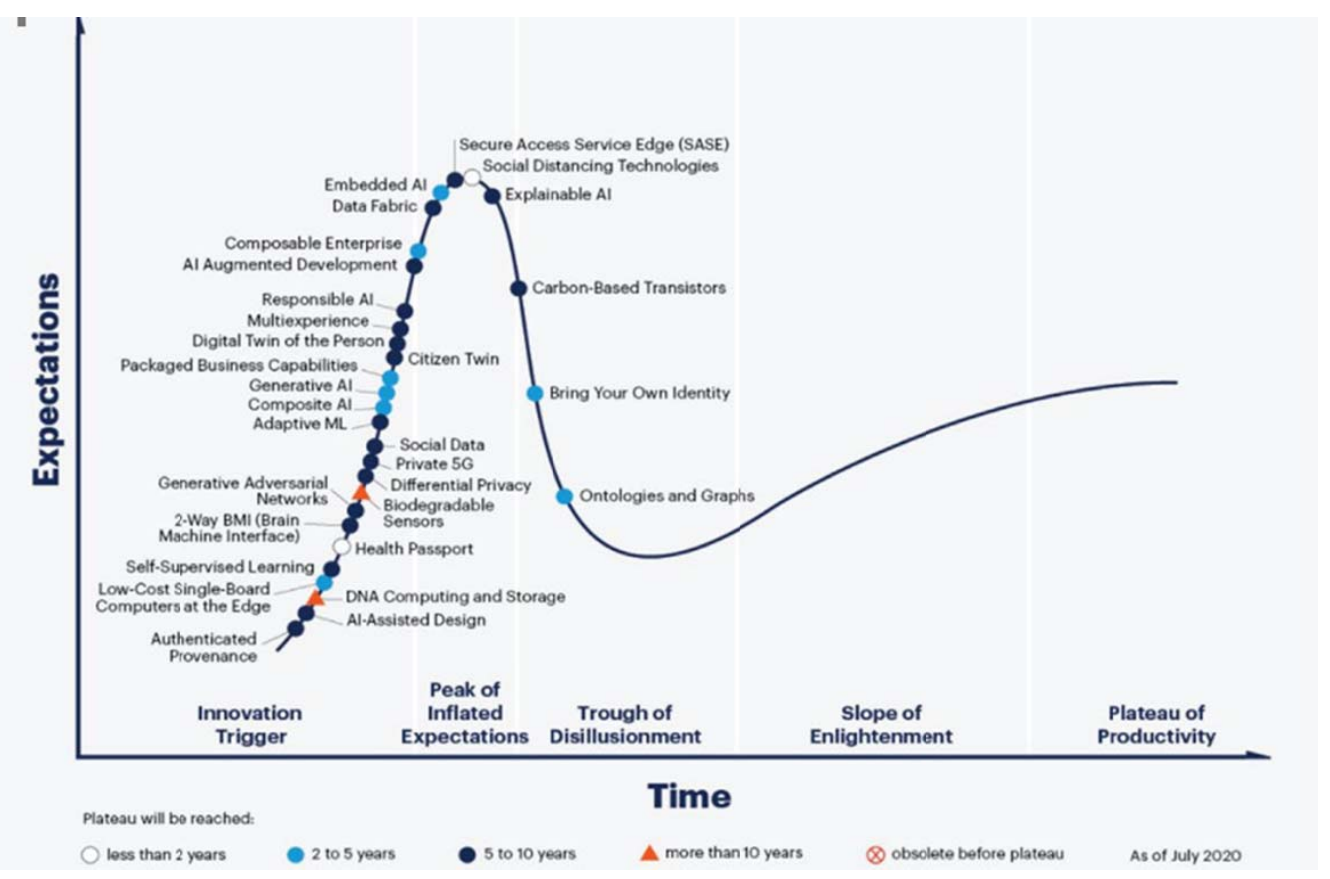

Figure no. 1: Hype cycle for emerging technologies, 2020

(Source: Adapted from Gartner 2021)

The data shows that Gartner's 2020 hype cycle for emerging technologies gleaned more than 1,700 distinctive technologies into a list of critical to understand technologies and trends (Panetta, 2020). See Table no. 1 for the five unique technologies are highlighted.

Table no. 1

Gartner's 2020 Five Unique Emerging Technologies

Composite Architectures

Algorithmic Trust

Beyond Silicon

Formative Artificial Intelligence (AI)

Digital Me
Provides enhanced increased business resilience.

Confirms assets on the blockchain and safeguards the assets authenticity

Applies DNA and biochemistry in place of silicon or quantum architectures to perform computation or store data

Data is encoded into synthetic DNA strands for storage and enzymes offer the processing capabilities through chemical reactions

A type of AI that can produce fresh original content (e.g., images, video etc.) or alter existing content.

Bidirectional brain-machine interfaces (BMIs) brain-altering wearables that permit two-way communication amid a human brain and a computer or machine interface

BMIs are as wearables or implants that monitor EEGs (electrical activity in the brain) and persons' mental states 
Composite Architectures, Algorithmic Trust, Beyond Silicon, Formative Artificial Intelligence (AI), and Digital Me (Panetta, 2020). Of these technologies, this text points out $\mathrm{AI}$ and $\mathrm{AR}$ as significant technologies that are expected to lead in emerging developments (Anderson \& Rainie, 2018; Karasinski et al., 2021). Also, reviewed is the need for both technologies as stand-a-lone, plus both as integrated technologies. Further reading offers more information for human capital development of cybersecurity leaders to be able to engage in the questioning of practices, scrutinize entrenched assumptions about technology, customary practices, and query technology's outputs by pursuing to comprehend all assumptions that could influence operations. Further, this text considers the gained knowledge of this review on the freshness of knowledge outcomes.

\section{Comprehending Intelligence (AI) \\ Artificial}

What cybersecurity leaders should know about AI? AI is being incorporated into innumerable industries - organizations, IT companies, financial services, healthcare, automotive, education, journalism, and others. This form of technology imitates the computational processes of the human brain (Burton, 2019). In other words, it is the simulation of what is known to be human intelligence processes; however, by machines (Dimiduk et al., 2018). How is this done? AI performs via a digital circuitry with the goal to create an authentic mindfulness within a system that is not biologically fixed. AI is a form of IT system intelligence that runs algorithms supported by past recorded data to calculate the best possible and most probable outcomes (Radziwill, 2019). Also, AI is termed as the imitation of human intelligence practices by machines, particularly computer systems. AI has particular applications - expert systems, natural language processing (NLP), speech recognition and machine vision (UiPath, 2018).
The programming of AI focuses on three cognitive skills - learning, reasoning, and self-correction. Learning references AI programming concentrated on obtaining information and establishing rules (algorithms) for how to turn the information into actionable data (Burt et al., 2018; Lu \& Burton, 2017). The rules offer step-by-step directives on how to fulfil a peculiar task. Even though machine learning is based on the notion that machines should be able to learn and adjust via involvement, AI denotes a wider idea such that machines can complete tasks cleverly (Dawson \& Szakonyi, 2021). AI applies various types of learning - machine learning, deep learning, plus additional methods to resolve definite concerns. Let's review reasoning.

For AI, reasoning references the functionality to draw conclusions suitable to the condition. Reasoning is vital in order for the machine to also think rationally akin to a human brain. In other words, the machine is expected to accomplish like a human, a trend of technology fast-forwarding along a path of no return (Fazzi, 2018). Conclusions of reasoning are termed as deductive, inductive, abductive, common sense, monotonic, and non-monotonic. According to Wang (2021) reasoning through AI programming centers on selecting the correct algorithm to determine a preferred conclusion. Last is machine vision.

Since the 1950s, machine learning references computers making sense of enormous amounts of data (AI Timeline, 2018; Cowan \& Nelson, 2010; Tsidulko, 2016). Over the years, programmers have progressively advanced the ability of machines to analyze data for the purpose of identifying patterns that permit computers to then systematize data, recognize relationships, make predictions and distinguish irregularities. Current technology, using AI has allowed the development of autonomous-driving vehicles (Lauterbach, 2019), enabled virtual assistants (Dash et al., 2019), supported the uncovering of fraud (Suresh \& Rani, 2020), and has directed resources such as electricity being more cost-effective (Ercan \& Samet, 2020). 


\section{Comprehending Augmented Reality (AR)}

What cybersecurity leaders should know about AR? Akin to AI, AR is being fused into countless industries - business, IT companies, financial services, healthcare, automotive, and others. This technology, which overlays representative looking objects onto the background setting of viewers presenting the impression that the computer-generated object is really a part of the real scene (Greenwald, 2018). Simply put, AR is an enriched account of the real physical world. This change is achieved via the application of digital visual elements, sound, or other sensory inducements produced by technology (Greenwald, 2018). AR signifies seeing actuality, however with other simulated things on top of the actuality (Gäthke, 2020). This technology is an intensification of actual images by offering more data about images/objects users may point their AR devices to (Dimiduk et al., 2018). Devices must be registered plus grounded on the GPS location and direction of the compass entering data about the images / object from the web, and shown on visual displays such as glass/computer displays. Essentially, the experience is reality but amplified by digital data (Brengman et al., 2019). For example, an AR experience can be looking into the lower windshield of a vehicle and seeing not only the speed travelled but the speed of the road and how close the driver's vehicle is to the surrounding vehicles. Noting Brengman et al., 2019, AR technology enable organizations' customers to position products in their own environments to determine how the products might fit, and then add the products to carts for purchase. The engineering, technology, and healthcare industries are using AR for training professionals who can see, through augmented vision, actual step-by-steps procedures.

\section{Linking Artificial Intelligence (AI) and Augmented Reality (AR)}

AI and AR are two distinct technologies that can stand alone. On the other hand, the bridging of the two technologies permits mobile app developers to create more interactive and interesting applications (Gäthke, 2020). What is the significant distinction? As posited by Gäthke, (2020), AI comprises algorithms and statistical models proficient to carrying out tasks minus precise instructions. Fundamentally, $\mathrm{AR}$ is an involvement that mergers physical and cybernated environments. Through AR, viewers experience a heightened version of the real physical world (Gäthke, 2020). Although AI promises to improve the access and quality of industries such as engineering, technology, and healthcare, the expenses of image digitization in certain areas continue as barriers to real-life application. An example of an expense area is pathology, as well as snags in deploying AI solutions. Examples of AI and AR cost effective connections exist (Gudoniene \& Rutkauskiene, 2019).

Human capital development of cybersecurity leaders should include knowledge that the field of technology is applying $\mathrm{AI}$ and $\mathrm{AR}$ for image recognition and image tracking in robotics. Nextgeneration robotics, with the utilization of computer vision and machine learning, are more complex and cutting-edge with their proficiencies to detect their surroundings, examine dynamic scenarios or changing conditions, and then ascertain a conclusion. As this technology advances, developers must continue to remain exceedingly educated in higher-level robotic vision functionality and tools for object detection and classification, and object tracking and navigation. Similar to engineering and technology, AI and AR overly is used in healthcare. 
As given by Wimalasena and Clements (2019), the field of healthcare is applying AI and AR overlay to propel widespread medical advances that are helping a myriad of patients. For example, HoloLens augmented reality (AR) glasses with clear lenses are used during surgery for the purpose of escalating the correctness of incisions during lower limb, and back procedures (Wimalasena \& Clements, 2019). Further significant to understand, according to Wimalasena and Clements (2019), is that a devoted AI chip is required for the HoloLens that has to be built to realize enormous amounts of complex data congregated by its depth and camera sensors void of latency.

Data from sources such as Pew Research, Brookings Institution, and other organizations show that the demand for AI and AR applications are positioned to sky-rocket (Anderson \& Rainie, 2018; Glaser \& Gerald, 2018; West \& Allen, 2018). For this reason, and to remain current in the technological sphere, the fields of engineering, technology, and healthcare should continue to seek the most up-to-date and appropriate software development kits (SDK) and application program interfaces (API). Maintaining current knowledge is significant for cyber leaders.

\section{5G Technology on Artificial} Intelligence (AI), and Augmented Reality (AR)

Ascending from innovation and computational power is the fifth industrial revolution (Ericsson, 2019), an innovative era of intelligent and super-intelligent machines. 5G, the 5 th generation mobile network, a wireless technology (Burton, 2019), an advancement from 4G (Muir, 2019), and a progression of AI and humanity, denoted as Industry 5.0 (Rossi, 2018 ) is being deployed around the world (Burton, 2019). This technology, permitting a new kind of network, is expected to significantly change the manner in that people live and work by meeting significant growth in data and connectivity due to the establishment of faster broadband speeds, which are one hundred times faster than $4 \mathrm{G}$ in terms of traffic capacity and network efficiency, decreased latency, along with amplified dependability and capacity (Ericsson, 2019).

The consequence of industry 5.0 on people is that organizations have highervalued jobs allowing employees the autonomy of design responsibility versus manufacturing processes (Rossi, 2018). $5 \mathrm{G}$ is changing the way we work and live. Human resource professionals are increasingly able to complete strategic tasks while AI handles on boarding solutions (Muir, 2019). More organizations are using human-robot collaboration (Nahavandi, 2019). Industries such as healthcare and automotive are applying AR overlays on computer-generated impressions, sounds, and texts which changes what a person would normally see (Joda et al., 2020; Skorenkyy et al., 2021).

Significant for the operation of the $5 \mathrm{G}$ technology on AI and AR applications is cybersecurity (Dawson \& Szakonyi, 2021; Radziwill, 2019). Across the board, organizations continue to struggle to avert increasingly intricate cybersecurity attacks (Muller, 2020). In order to make wellinformed decisions and function as vital performers, cybersecurity leaders, across the board, must gain and maintain an understanding of the workings of $\mathrm{AI}$ and $\mathrm{AR}$ technology (Bhatia, 2018). While technicians handle programming and the daily working of the technology, cybersecurity leaders must understand this technology enough to ask the right questions and guide their respective organizations toward the best solutions (Burton, 2021). Due to the changes enabled by $5 \mathrm{G}$, disruptive technology development is expected to continue into the next decade (Glaser \& Gerald, 2018). 


\section{Implications for future research}

Through constant research and learning cybersecurity leaders can remain wellinformed of technological metamorphosis as digital transformation trends continue to disrupt the actions of people, the formation of processes, and the functioning of technologies. This developing knowledge can support cybersecurity leaders to become forward-thinking and become better at hindering direct and indirect cyberattacks. This article has reviewed evidence-based information listing, noting, specifying, and particularizing disruptions in the technological space so that cybersecurity leaders can better understand how to meet strategic technological requirements, plus better support ever-evolving knowledge changes in this digitized world. Learning has to endue to reflect and support novel methods for evolved threats. Adding to this comparative analysis, other research is needed to maintain a full range of technological understanding.

The first area needing more research is the use and application of AI technology. Organizational leaders need more understanding of AI such as scaling analytics and automation, as well as the data that energizes the connections to embolden all cybersecurity leaders to understand diverse technological processes. This enhanced knowledge can support decisions regarding the application of AI to alter the fundamental functions of what organizations do plus how and why they perform work in a specific manner. Also this knowledge can help cybersecurity leaders better understand how to remain competitive and to remain a viable organization. New knowledge should include understanding AI strategy, the need for diverse teams, as well as the look and feel of ethical frameworks fabricated within the AI.

The second area needing more research and comparative analysis is machine learning vs. deep learning vs. natural language processing. Leaders might believe the technology is needed; however, not understand that each area is a part of the AI backdrop is progressing the length of its own path. What needs to be detailed is how can the combination of these functions through data, analytics, and automation support cybersecurity leaders' knowledge banks to accomplish goals such as enhancing customer service and augmenting the overall supply chain. Through increased and significant understanding, professionals lacking AI understanding become equipped to discover vital data to improve organizational efficiency (Murawski, 2019).

A third and final area needing more research and comparison is AR, a collaborative three dimensional (3D) involvement that joins a view of the real world with computer-generated components. Cybersecurity leaders need to understand this technology's value, specifically the manner in which AR can decipher, manipulate, and enrich the belief of the real world in real time. Through advanced learning cybersecurity leaders can learn to enhance customer experiences, increase revenue, gain sustainability, and drive forward competitiveness. The knowledge of these four points have the potential for cybersecurity leaders to learn more about using technology for customers to try on products, determine how products may appear in their homes and offices, overlay navigation information on vehicle windshields, view 3D information in books to gain better comprehension, or overlaying information on a person's field of view to learn or perform a task. Significant is the present need for cybersecurity leaders to increase their knowledge, skills, and abilities to successfully guide organizations through the pitfalls of cyberattacks, being effective players in their perspective industries (Anderson \& Rainie, 2018; Murawski, 2019; Muller, 2020; West \& Allen, 2018).

To be significant leaders, cybersecurity leaders must be knowledgeable and have a seat at the table for all aspects touching the industries' futures (Burton, 2019). The benefits to be gained from cross-technology research include a wider comprehension of other technologies and of their application processes. 


\section{Conclusion}

What do cybersecurity leaders need to understand regarding human capital development? Despite the fact that AI and $\mathrm{AR}$ are individual technologies, these technologies can sync with one another on a diversity of applications. One can influence the other's best physiognomies, and components forming unconceivable mobile experiences. AI enables AR to have pluridimensional relations with the physical environment. The interaction permits the manipulation of $2 \mathrm{D}$ and $3 \mathrm{D}$ virtual objects with words, eyes, and the hands. AI and AR are being integrated in numerous ways. Examples include but are not limited to the following: learning and education; human pose estimation; image recognition and image tracking; object recognition; speech recognition; recognizing and labelling; and vehicle recognition. These interactions are driving change in fields such as engineering, technology, journalism, and healthcare, as well as for overall organizational operations such as analyzing demographics of applicant pools, assembly, filtering resumes, maintenance, repair, security, stocking, surgery, warehousing, etc.

The result of this delimited cybersecurity human capital development reveals that information exists for cybersecurity leaders to understand and continue to build skillsets regarding AI and AR. Because of $5 \mathrm{G}$, these technologies are revolutionizing the manner in which the world functions. Ubiquitous technology is striking most every field; therefore, new information is continuously required to fill knowledge gaps (Uzialko, 2019). Technology continues to assimilate into every single aspect of human life. The comprehension as to if the assimilation is entirely beneficial and gainful remains an indefinite. An unquestionable point is that the world is dependent upon technology. Whether separate or through overlay, the budding anytime and anyplace usage of AI and AR can be credited to increased processing power and the diminishing cost of realizing such tasks at amplified paces.

\section{REFERENCES}

AI Timeline. (2018). Modern healthcare. Vol. 48, Issue 10, 20, available at: https://proxy. cecybrary.com/login?url=https://search-proquestcom.proxy.cecybrary.com/docview/201172 4980? accountid $=144459$

Anderson, J., \& Rainie, L. (2018). Artificial intelligence and the future of humans. Pew Research Center, available at: https://www.pewresearch.org/internet/2018/12/10/ artificial-intelligence-and-the-future-of-humans/

Bhatia, G. (2018). How Internet of Things (IoT) will impact HR? Emptrack, available at: https://empxtrack.com/blog/how-internet-of-things-will-impact-human-resources/

Brengman, M., Willems, K., \& Van Kerrebroeck, H. (2019). Can't touch this: The impact of augmented reality versus touch and non-touch interfaces on perceived ownership. Virtual Reality, Vol. 23, Issue 3, 269-280.

Burt, A., Veale, M., Stiefel, M., \& Williams, R. (2018). Can people trust the automated decisions made by algorithms? Info $Q$, available at: https://www.infoq.com/articles/CanPeople-Trust- Algorithm-Decisions/

Burrell, D.N. (2018). An exploration of the cybersecurity workforce shortage. International Journal of Hyperconnectivity and the Internet of Things, Vol. 2, Issue 1, available at: https://dl.acm.org/doi/10.4018/IJHIoT.2018010103 
Burrell, N.N. (2021). Cybersecurity leadership from a talent management organizational development lens. (Unpublished Exegesis). Capitol Technology University.

Burton, S.L. (2019). Grasping the cyber-world: Artificial intelligence and human capital meet to inform leadership. International Journal of Economics, Commerce and Management, Vol. 7, Issue 12.

Burton, S.L. (2021). Artificial intelligence (AI) and augmented reality (AR): Disambiguated in the telemedicine/telehealth sphere.

Choi, J., Lung, H., Kaplan, J., Krishnamurphy, C., Pahwa, S., \& Rezek, C. (2019). Perspectives on transforming cybersecurity. McKinsey \& Company, available at: https://www.mckinsey.com/ /media/McKinsey/McKinsey\%20Solutions/Cyber\%20Solutions/ Perspectives $\% 20$ on $\% 20$ transforming\%20cybersecurity/Transforming $\% 20$ cybersecuri ty March2019.ashx

Cowan, J., \& Nelson, J. (2010). The company of the future. Canadian Business, Vol. 83, 32-36, available at: https://proxy.cecybrary.com/login?url=https://search-proquestcom.proxy. cecybrary.com/docview/864296898?accountid=144459

Dash, R., McMurtrey, M., Rebman, C., \& Kar, U. K. (2019). Application of artificial intelligence in automation of supply chain management. Journal of Strategic Innovation and Sustainability, Vol. 14, Issue 3, 43-53, available at: https://www.proquest.com/scholarlyjournals/application-artificial-intelligence-automation/docview/2306438509/se-2?accountid=167615

Dawson, M., Bacius, R., Gouveia, L.B., \& Vassilakos, A. (2021). Understanding the challenge of cybersecurity in critical infrastructure sectors. Land Forces Academy Review, Vol. 25, Issue 101, 69-75. DOI: 10.2478/raft-2021-0011

Dawson, M., \& Szakonyi, A. (2020). Cybersecurity education to create awareness in artificial intelligence applications for developers and end users. Scientific Bulletin, Vol. 25, Issue 2, 85-92. https://doi.org/10.2478/bsaft-2020-0012

Dimiduk, D.M., Holm, E.A., \& Niezgoda, S.R. (2018). Perspectives on the impact of machine learning, deep learning, and artificial intelligence on materials, processes, and structures engineering. Integrating Materials and Manufacturing Innovation, Vol. 7, Issue 3, 157-172. DOI: http://dx.doi.org.proxy.cecybrary.com/10.1007/s40192-018-0117-8

Ercan, O., \& Samet, G. (2020). Literature review of industry 4.0 and related technologies. Journal of Intelligent Manufacturing, Vol. 31, Issue 1, 127-182. DOI: http://dx.doi.org/10.1007/s10845-018-1433-8

Ericsson. (2019). Bridging the cellular generation gap. The New York Times, available at: https://www.nytimes.com/paidpost/ericsson/bridging-the-cellular-generation-gap.html

Fazzi, C. (2018). 3 things you need to know about Industry 5.0. MasterControl, available at: https://www.mastercontrol.com/gxp-lifeline/3-things-you-need-to-know-aboutindustry-5.0/

Gäthke, J. (2020). The impact of augmented reality on overall service satisfaction in elaborate servicescapes. Journal of Service Management, Vol. 31, Issue 2, 227-246. DOI: http://dx.doi.org/10.1108/JOSM-05-2019-0151

Gartner. (2021a). Gartner equips executives across the enterprise to make the right decisions and stay ahead of change. Author, available at: https://www.gartner.com/en/ research/methodologies/gartner-hype-cycle

Gartner. (2021b). Gartner hype cycle. Author, available at: https://www.gartner.com/ en/research/methodologies/gartner-hype-cycle

Glaser, J., \& Gerald, C.K. (2018). Experimenting with artificial intelligence in health care. Cambridge: Massachusetts Institute of Technology, available at: https://proxy.cecybrary.com/ login?url=https://searchproquest-com.proxy.cecybrary.com/docview/2032519876?Accountid $=144459$ 
Greenwald, T. (2018). Artificial intelligence (A special report) - what exactly is artificial intelligence, anyway? Everybody's talking about AI these days. here's what all the fuss is about. Wall Street Journal, available at: https://proxy.cecybrary.com/login?url $=$ https://search-proquest-com.proxy.cecybrary.com/docview/2032327288?Accounted=144459

Gudoniene, D., \& Rutkauskiene, D. (2019). Virtual and augmented reality in education. Baltic Journal of Modern Computing, Vol. 7, Issue 2, 293-300. DOI: http://dx.doi.org/10.22364/bjmc.2019.7.2.07

Heathcare Information Management Systems Society (HIMSS). (2021a). Cybersecurity in healthcare. Author, available at: https://www.himss.org/resources/cybersecurity-healthcare

Hellard, B. (2018). AI news: AI technologies are 2018's biggest tech trends. IT Pro, available at: https://www.proquest.com/magazines/ai-news-technologies-are-2018s-biggesttech/docview/2090891694/se-2?accountid=167615

Joda, T., Bornstein, M.M., Jung, R.E., Ferrari, M., Waltimo, T., \& Zitzmann, N.U. (2020). Recent trends and future direction of dental research in the digital era. International Journal of Environmental Research and Public Health, Vol. 17, Issue 6, 1987. DOI: http://dx.doi.org/10.3390/ijerph17061987

Karasinski, J.A., Torron Valverde, I.C., Brosnahan, H.L., Gale, J.W., Kim, R., Yashar, M., \& Marquez, J.J. (2021). Designing procedure execution tools with emerging technologies for future astronauts. Applied Sciences, Vol. 11, Issue 4, 1607. DOI: http://dx.doi.org/10.3390/app11041607

Lu, S. \& Burton, S. L. (2017). Man vs robot? Future challenges and opportunities with artificial intelligence (A.I.) health care education model. Working Papers Human Development a Multidisciplinary Research. Research Association for Interdisciplinary Studies, available at: https://ideas.repec.org/s/smo/npaper.html

Muller, S.R. (2020). A Perspective On the intersection of information security policies and IA awareness, factoring in end-user behavior. Proceedings of the International Conference on Research in Management \& Technovation, 137-142. DOI: 10.15439/ 2020KM1

Morris-Reade, R. (2021). New research finds $93 \%$ of security leaders don't report to the CEO. Security Brief New Zealand, available at: https://securitybrief.co.nz/story/newresearch-finds-93-of- security-leaders-don-t-report-to-the-ceo

Muir, G. (2019). AI - The fifth industrial revolution. AI Business, available at: https://aibusiness.com/livetiles-fifthindustrial-revolution/

Nadaban, S. (2021). From classical logic to fuzzy logic and quantum logic: A general view. International Journal of Computers, Communications and Control, Vol. 16, Issue 1, DOI:http://dx.doi.org/10.15837/ijccc.2021.1.4125

Nahavandi, S. (2019). Industry 5.0- A human-centric solution. (Published Paper, Institute for Intelligent System Research and Innovation). Creative Commons Attribution. https://www.mdpi.com

National Initiative for Cybersecurity Careers and Studies. (n.d.). Cyber Operational Planning. Author, available at: https://niccs.cisa.gov/workforce-development/cyber-securityworkforce-framework/cyber-operational-planning

Nowduri, S. (2018). Critical thinking skills and best practices for cyber security. International Journal of Cyber-Security and Digital Forensics, Vol. 7, Issue 4, 39, available at: https://link.gale.com/apps/doc/A603050344/AONE?u=anon a10ef379\&sid=googleScholar $\underline{\text { \&id }=13 \mathrm{fb} 4 \mathrm{e} 04 . \text { Accessed } 2 \text { July } 2021 .}$.

Olsen, T. (2020). Understanding the digital transformation. Chemical Engineering Progress, Vol. 116, Issue 9, 29-35, available at: https://search.proquest.com/scholarlyjournals/understanding-digital-transformation/docview/2462457666/se-2?accountid=167615 
Panetta, K. (2020). 5 trends drive the gartner hype cycle for emerging technologies. Available at: https://www.gartner.com/smarterwithgartner/5-trends-drive-the-gartner-hypecycle-for- emerging-technologies-2020/

Petersen, R., Santos, D., Smith, C., Wetzel, K.A., \& Witte, G. (2020). Workforce Framework for Cybersecurity (NICE Framework). NIST, available at: https://nvlpubs.nist.gov/nistpubs/SpecialPublications/NIST.SP.800-181r1.pdf

Radziwill, N. (2019). Quality considerations for ethical design of virtual and augmented reality. Software Quality Professional, Vol. 21, Issue 4, 34-47, available at: https://search.proquest.com/scholarly-journals/quality-considerations-ethical-design-

virtual/docview/2312156997/se-2?accountid=167615

Rossi, B. (2018). What will Industry 5.0 mean for manufacturing? Raconteur, available at: https://www.raconteur.net/technology/manufacturing-gets-personal-industry-5-0

Saldaña, J. (2018). Writing qualitatively the selected works of Johnny Saldaña. CRC Press Taylor \& Francis Group.

Sanku, B.R. (2019). Research output of biological science during 1901-1945. A scientometric analysis. DESIDOC Journal of Library \& Information Technology, Vol. 39, Issue 3, 96-103. DOI: http://dx.doi.org/10.14429/djlit.39.3.14065

Sheladiya, C. (2019). AI can impact mobile app development and user experience. San Jose: Newstex, available at: https://www.proquest.com/blogs-podcasts-websites/ai-canimpact-mobile-app- development-user/docview/2297147907/se-2?accountid=167615

Shoard, P. (2020). Hype cycle for network security, 2020. Gartner Research. Available at: https://www.gartner.com/en/documents/3986990/hype-cycle-for-network-security-2020

Shu-Hoa, C. (2019). Revealing development trends and key 5G photonic technologies using patent analysis. Applied Sciences, Vol. 9, Issue 12. DOI: http://dx.doi.org/ $\underline{10.3390 / a p p 9122525}$

Skorenkyy, Y., Kozak, R., Zagorodna, N., Kramar, O., \& Baran, I. (2021). Use of augmented reality-enabled prototyping of cyber-physical systems for improving cybersecurity education. Journal of Physics: Conference Series, Vol. 1840, Issue 1. DOI:http://dx.doi.org/10.1088/1742-6596/1840/1/012026

Stephens, K. (2020). Densitas, mammography educators, link up for AI-powered telehealth training platform. AXIS Imaging News, available at: https://www.proquest.com/ scholarly-journals/densitas-mammography-educators-link-up-ai-powered/docview/24622 $\underline{53792 / \text { se-2?accountid }=167615}$

Suresh, A., \& Rani, N.J. (2020). Role of artificial intelligence (AI) in the Indian banking scenario. Journal of Information Technology and Economic Development, Vol. 11, Issue 2, 1-11, available at: https://www.proquest.com/scholarly-journals/role-artificial-intelligence-aiindian- banking/docview/2464655093/se-2?accountid=167615

Tsidulko, J. (2016). The race is on: IBM, Google, Microsoft and AWS aim to deliver machine learning as a cloud service. Available at: https://www.crn.com/news/cloud/ 300081289/the-race-is-on-ibm-google-microsoft-and-aws-aim-to-deliver-machine-learningas-a-cloud-service.htm

UiPath. (2018). Robotic automation awareness (RPA). Author, available at: https://cdn2.dcbstatic.com/dcd/scormapi v60/launcher full.html?host=academy.uipath.com\& id user $=341647 \&$ id reference $=5985 \&$ scorm version $=1.3 \&$ id resource $=34 \&$ id item $=34 \&$ ids corm organization $=34 \&$ id package $=34 \&$ launch type $=$ fullscreen $\&$ id course $=638 \&$ player $=$ hy dra\&autoplay enabled $=0 \&$ name $=$ rpa-starter training \& return $u r l=$ academy. uipath com\&as json=1\&auth code $=a 6 c 60 b c a 4 c 66 e 85 e 4 f 62 f 380 \mathrm{c} 15 \mathrm{~d} 960 \mathrm{ed} 4 \mathrm{a} 8 \mathrm{a} 4 \mathrm{e} 7 \&$ debug $=1$

Uzialko, A.C. (2019, February 19). Workplace automation is everywhere, and it's not just about robots. Business Daily News, available at: https://www.businessnews daily.com/9835-automation-tech-workforce.html 
Wagner, D.N. (2020). The nature of the artificially intelligent firm - an economic investigation into changes that AI brings to the firm. Telecommunications Policy, Vol. 44, Issue 6, 1. DOI:http://dx.doi.org/10.1016/j.telpol.2020.101954

Waltner-Toews, D. (2017). Zoonoses, one health and complexity: Wicked problems and constructive conflict. Philosophical Transactions of the Royal Society B 372: 20160171.

Wang, Y. (2021). Artificial intelligence in educational leadership: A symbiotic role of human- artificial intelligence decision-making. Journal of Educational Administration, Vol. 59, Issue 3, 256-270. DOI:http://dx.doi.org/10.1108/JEA-10-2020-0216

West, D.M., \& Allen, J. J. (2018). How artificial intelligence is transforming the world. Brookings Institute, available at: https://www.brookings.edu/research/how-artificialintelligence-is-transforming-the-world/

Wigmore, I. (2021). Gartner hype cycle. TechTarget, available at: https://whatis.techtarget.com/definition/Gartner-hype-cycle

Wimalasena, N.K., \& Clements, R. (2019). Augmented Medicine: The power of augmented reality in the operating room. SITNBoston, available at: https://sitn.hms. harvard.edu/flash/2019/augmented-medicine-the-power-of-augmented-reality-in-theoperating-room/.

Wu, S., \& Neilsen, M.L. (2019). Augmented reality for high-throughput phenotyping. Athens: The Steering Committee of the World Congress in Computer Science, ComputerEngineering and Applied Computing (WorldComp). Available at: https://www.proquest. com/conference-papers-proceedings/augmented-reality-high-throughput-phenotyping/ docview/2277993997/se-2?accountid=16761 emerging-technologies-2020/ 